Resenha

\title{
Gestão como doença social: ideologia, poder gerencialista e fragmentação social
}

GAULEJAC, Vincent de. Tradução: Ivo Storniolo. Aparecida, SP: Ideias \& Letras, 2007. 338 p. ISBN: 978-85-98239-97-2.

Pouco conhecido no âmbito das Ciências Sociais no Brasil, o livro A gestão como doença social, ${ }^{1}$ do sociólogo francês Vincent de Gaulejac, contribui elucidativamente para a reflexão acerca da relação entre saúde e condições de trabalho. Embora seja construído em estilo ensaístico, carecendo por vezes de fundamentação conceitual mais rigorosa, é profícuo em insights que desvendam os atuais mecanismos de dominação do novo modelo de gestão proposto pelo capitalismo financeiro, bem como suas legitimações ideológicas. Estas discussões, tanto quanto aquelas referentes às transformações econômicas das últimas décadas, não são inéditas. Foram expostas anteriormente por autores consagrados - tais como Robert Castel, Alain Ehrenberg, Richard Sennet, Ulrich Beck, Boltanski e Chiapello -, os quais a leitura do livro de Gaulejac não dispensa, mas que, todavia, resume de forma bastante didática.

Na primeira parte, a gestão é apresentada como uma tecnologia de poder. Ela própria seria uma ideologia que legitima a mercantilização do ser humano, transformando-o em "capital que convém tornar produtivo” (p. 28). A gestão da qual trata o livro refere-se a um conjunto de técnicas e saberes práticos utilizados nos setores de recursos humanos de grandes empresas, visando orientar condutas e estabelecer uma "cultura corporativa" (p. 20) que mobilize as subjetividades para a realização de um ideal de indivíduo adequado às exigências da nova ordem econômica, ou seja: autônomo, polivalente, criativo, que assuma responsabilidades e arque com riscos. Flexível o suficiente para contornar a instabilidade atual do sistema econômico e superar-se em frequentes situações de adversidade. Em outros termos: um super-humano, que faça sempre melhor e mais rápido.

No atual estágio do capitalismo, a guerra econômica serve de justificativa para o empoderamento empresarial frente a outras instituições e para os sacrifícios exigidos dos trabalhadores. O avanço das tecnologias informáticas e de telecomunicações instituiu uma "ditadura do tempo real" (p. 41); o lucro deve ser imediato e os prazos são cada vez mais curtos. A economia já não está a serviço do desenvolvimento da sociedade, torna-se um fim em si, para o qual toda a sociedade deve se direcionar (p. 27). O ritmo da vida individual, social e institucional passa a ser determinado pelo ritmo das corporações.

Supõe-se que a experiência humana possa ser traduzida em cálculo. Os índices e os indicadores meritocráticos converteram o ser humano em fator econômico equivalente à matéria-prima e às ferramentas de produção. A objetividade numérica travestida de neutralidade emula uma circunstância igualitária de avaliação, na qual todos possuem as mesmas chances e são tratados da mesma maneira. Porém, a finalidade máxima de lucro prepondera sobre o valor imaterial intrínseco à vida humana. Os indicadores são instrumentos objetivos que escondem a irracionalidade das metas irrealistas e a arbitrariedade das regras empresariais, pois à liberalização total do capital corresponde uma desregulamentação do trabalho (p. 58).

A “ciência gerencial” (p. 66) - que se institui como área de conhecimento após a década de 1960 trabalha com um ideal de indivíduo que se comporta racionalmente e que é capaz de alcançar sempre mais. Convida-se o indivíduo ao autoaperfeiçoamento incessante e ao gerenciamento racional de si mesmo como se ele próprio fosse uma empresa privada. Predomina o culto da excelência, no qual se incita não apenas a fazer melhor, mas a ser "o" melhor em comparação com outros e consigo mesmo em fases anteriores (p. 84). A exigência de excelência - que jamais pode ser satisfeita, pois sempre é possível melhorar - esconde-se sob o conceito de qualidade. A armadilha residiria no discurso da busca infinita de qualidade, hegemônico nos meios empresariais desde os anos 1990, ao qual dificilmente se pode opor, uma vez que se mostra como realização de um ideal naturalmente humano. A qualidade, enfim, aparece sempre como melhoria, como progresso e não como pressão. Entretanto, essa noção de qualidade é uma utopia de perfeição que remete a um paraíso per- 
dido, a um mundo harmônico e sem contradições, no qual os conflitos são definitivamente superados, conforme assinala Gaulejac (p. 105).

Gerenciar a si mesmo para atingir alto desempenho é uma demonstração de autonomia recompensada pela promessa de sucesso, felicidade e realização pessoal. Essa suposição provém de uma espécie de "equação mágica" (p. 82) que obscurece a impossibilidade de sermos todos excelentes. Luta-se pelos lugares como se todos pudessem ser o número um. Esquece-se que a própria etimologia da palavra excelência comporta intrinsecamente a exclusão daqueles que não atingem determinados requisitos. $\mathrm{O}$ culto da qualidade enquanto excelência estimula, portanto, a competição generalizada e o individualismo.

Hoje, a gestão é um modo de relação com o mundo e consigo mesmo que busca racionalizar e otimizar o tempo, o corpo, a mente, a subjetividade, as relações, de modo a tornar a vida mais rentável, mais útil e competitiva na perspectiva de empregabilidade. $\mathrm{O}$ novo modelo empresarial de organização se impõe à sociedade, substituindo antigos padrões do exército e das fábricas. As forças produtivas já não estão no corpo, estão na psique. Já não se trata de uma empresa disciplinar, nos moldes descritos por Foucault, mas de um modelo gestionário flexível que pretende seduzir o corpo e a alma, envolver a psique e orientá-la para a capitalização das empresas (p. 110).

Na segunda parte do livro, o autor questiona os motivos que teriam levado a sociedade a aderir ao modo de gestão em suas mais variadas esferas - política, educação, saúde, família, afetos. "Gestão é um sistema de interpretação do mundo social” (p. 64), diz Gaulejac, comporta uma "visão de mundo e um sistema de crenças" (p. 65) que oferecem uma ilusão de onipotência e de poder. Ao contrário da gestão disciplinar, que atuava no superego de maneira a impor ordens e reprimir o desejo, o novo formato de gestão propõe regras que excitam o ego, prometendo-lhe satisfação do desejo sem limites. A energia libidinal é canalizada para o trabalho como forma de realização pessoal subjetiva, o que o autor denomina de "ideologia da realização de si mesmo" (p. 77).

A nova gestão mobiliza "o gosto humano por empreender, o desejo de progredir, a celebração do mérito ou o culto da qualidade" (p. 81). O investimento psíquico em desempenho de excelência e autonomia funcionaria, então, como reforço narcísico. Conforme Gaulejac, o sucesso do novo modelo deve-se à confusão entre o desejo de reconhecimento e uma fantasia narcísica de onipotência que é projetada nas empresas e reiterada pelo discurso de que o crescimento pessoal do indivíduo corresponde ao crescimento da corporação. A autonomia idealizada pelos setores de recursos humanos é uma identificação do indi- víduo com a empresa. Uma "autonomia controlada" (p. 92) que gera uma forma de dependência psíquica, pois, para ser reconhecido como produtivo e excelente, o indivíduo deve submeter-se a critérios de qualidade que não são estabelecidos por ele.

A doença social mencionada no título refere-se aos paradoxos criados por esse formato de gestão e ao acobertamento da violência simbólica pelas novas regras do trabalho flexível. Os problemas sociais e os conflitos são transferidos para o plano individual e são tratados como distúrbios pessoais. Por outro lado, o fracasso abre uma ferida narcísica, estigmatiza o perdedor como um peso social, pois já não é permitido ser limitado. O método de quantificação da qualidade opera pela desqualificação do que é humano, pela ameaça de avaliação negativa, culpabilizando os desempregados, os precarizados e os assalariados por sua insuficiência e inaptidão para alcançar metas inacessíveis.

Os paradoxos propostos pela gestão hipermoderna podem ser considerados, por si, fatores de adoecimento físico ou psíquico à medida que a pressão exercida pelas exigências empresariais é perturbadora e estimula a construção de uma "subjetividade fluida" (p. 187). Gaulejac afirma, entretanto, que a adesão total aos princípios e às regras das empresas ocorre apenas "de fachada" (p. 135). Em grande parte dos casos, os indivíduos se fragmentam internamente ou mergulham na hiperatividade para não pensarem na dinâmica de uma situação da qual não têm como sair. A ação contínua é fortemente estimulada, pois a estagnação representa fracasso. Mas quando o "sentido da ação se resume em ser campeão” (p. 169), advém daí uma crise simbólica que retira o significado da própria vida.

Não é à toa que na Saúde Pública anuncia-se uma epidemia de distúrbios psíquicos. O discurso do gerenciamento pela qualidade é circular e enlouquecedor em suas inúmeras ambiguidades. A lógica qualitativa do discurso choca-se com a lógica quantitativa da prática. Enaltece-se o valor humano e busca-se o lucro máximo a qualquer custo. Pede-se "autonomia em um mundo hipercoercitivo" (p. 117), criatividade "em um mundo hiper-racional" (p. 117), compromisso intenso com os projetos da empresa e flexibilidade para desligar-se a qualquer instante. O individuo é livre para, enfim, seguir um programa imposto de qualidade máxima.

Diversos distúrbios e enfermidades atingem os desempregados e aqueles que permanecem ativos no mercado profissional, porém submetidos a alto nível de estresse. O estresse, todavia, não é considerado um problema; é antes uma decorrência "natural" (p. 221) da busca legítima por um lugar de excelência e autorrealização. Cabe a cada um se adaptar e 
gerenciar seu nível de estresse, resistindo à vulnerabilidade psíquica ocasionada pelas condições de trabalho. Como se sabe, as doenças psicossomáticas decorrentes do trabalho são de difícil comprovação. A gestão de si e o autocuidado com a saúde física e psíquica apresentam-se, então, como solução para um problema que a própria atividade de gestão cria. Novamente é o ideal da qualidade de vida, também medida por índices, que alerta o quão se pode ser mais saudável: só depende de cada um aplicar o método milagroso da gestão racional em si mesmo.

Embora Gaulejac siga uma linha de crítica contundente ao longo do livro, repete mais de uma vez que a "gestão não é um mal em si” (p. 29, p. 144). Conclama a substituição da "gestão de recursos humanos" por uma "gestão humana de recursos" (p. 145) de forma a construir "outro mundo possível” (p. 299), para o qual a Sociologia poderia contribuir. Ao final, entretanto, fica a impressão de que o autor foi, enfim, também ele contaminado pelo vírus da qualidade, sucumbindo ao mito da terra sem males, sem conflitos, sem contradições, sem ideologias, onde pudesse haver uma gestão que não fosse permeada por técnicas de dominação e exercício do poder. Apesar destas considerações, fica aqui a recomendação de leitura, certamente inspiradora tanto para a Sociologia do Trabalho, quanto para a Sociologia da Saúde.

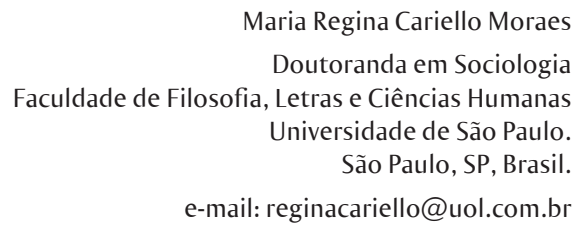

